\title{
Sanfilippo syndrome type D in two adolescent sisters
}

Luisa Siciliano, Agata Fiumara, Lorenzo Pavone, Craig Freeman, Daniel Robertson, C Phillip Morris, John J Hopwood, Paola Di Natale, Salvatore Musumeci, Allen L Horwitz

\begin{abstract}
We report on two adolescent sisters with Sanfilippo syndrome type $D$ with some clinical features different from other cases previously described. They are the oldest cases reported to date and provide new clues about the course of the disease. Enzymatic and immunological characterisation of the patients' fibroblasts indicated deficiency of $\mathrm{N}$ acetylglucosamine-6-sulphate sulphatase (GIcNAc6S sulphatase). However, Northern blot analysis showed apparently normal mRNA encoding GlcNAc-6S sulphatase. These findings suggest that abnormal translation or premature degradation may be responsible for the enzyme defect in these cases of Sanfilippo syndrome type D.
\end{abstract}

Sanfilippo syndrome (mucopolysaccharidosis III) is a hereditary disorder of mucopolysaccharide metabolism characterised by heparan sulphate accumulation in tissues and excretion in urine. It is caused by deficiency of lysosomal enzymes required for heparan sulphate degradation. Four types of Sanfilippo syndrome are distinguished by the enzymatic defect: 2-deoxyglucoside-2-sulphamate sulphatase is deficient in type $\mathrm{A}, \alpha-\mathrm{N}$-acetylglucosaminidase in type $\mathrm{B}$, acetyl-CoA: $\alpha$-glucosaminidase- $\mathrm{N}$-acetyl-transferase in type $C$, and GlcNAc-6S sulphatase in type D. The clinical picture, consisting of mental retardation and mild somatic and visceral involvement, is similar in all

Joseph P Kennedy Jr Mental Retardation Research Center, Department of Pediatrics, University of Chicago, USA.

L Siciliano, A L Horwitz

Department of Pediatrics, University of Catania, Italy. A Fiumara, L Pavone, S Musumeci

Department of Chemical Pathology, Adelaide Children's Hospital, North Adelaide, Australia.

C Freeman, D Robertson, C P Morris, J J Hopwood

Department of Biochemistry and Medical Biotechnology, 2nd Medical School, University of Naples, Italy. P Di Natale

Correspondence to Dr Siciliano, Clinica Pediatrica, Città Universitaria, Viale Andrea Doria 6, 95100 Catania, Italy.

Received for publication 26 April 1990.

Revised version accepted for publication 1 November 1990. four types so that the specific diagnosis is essentially biochemical. ${ }^{1}$

So far, only six patients with Sanfilippo syndrome type $D$, aged 1 to 11 years, have been clinically described. ${ }^{2-4}$ Our report of two adolescent sisters affected with Sanfilippo syndrome type D expands the clinical spectrum and provides some clues about the quality and the expectancy of life in this disease.

Although GlcNAc-6S sulphatase has been well characterised $^{5}$ and cDNA has been obtained, ${ }^{6}$ individual cases of Sanfilippo type D disease have not been analysed at the molecular level.

In order to investigate the basis for the enzyme deficiency we have performed immunochemical and molecular studies on our patients' cells.

\section{Case reports}

\section{CASE 1}

Patient 1 is a 19 year old girl of Italian origin, the first born of consanguineous (first cousins), healthy parents. The patient was born post-term by forceps delivery. The birth weight was $3200 \mathrm{~g}$. The child's early milestones were mildly delayed: she was able to stand up at 1 year and to walk by herself at 2 years. Speech began at the age of $2 \frac{1}{2}$ years and was limited to a few words. At the age of 4 the patient started to show progressive speech loss and aggressive behaviour. The regression of her psychomotor skills proceeded over a few years to a complete loss of contact with her environment and inability to walk unaided by the age of 10 years. The clinical examination showed: height $141 \mathrm{~cm}(<3$ rd centile), weight $4500 \mathrm{~g}$ (25th centile), and head circumference $54 \mathrm{~cm}$ (50th centile). The face was coarse and the hair was thick, curly, and dark with a low hairline. The eyebrows were thick with synophrys. She had a wide, flat nasal bridge, thick lips, and full cheeks (fig 1A). Generalised hirsutism was present and the skin was cold to the touch. The hands were small and stubby and the feet had bilateral syndactyly of the third and fourth toes. Limitation of joint movements was present. The cardiac examination showed a grade $2 / 6$ systolic ejection murmur located over the third to fourth intercostal space of the parasternal line. EKG showed sinus bradycardia. Hepatosplenomegaly was absent. Neurological examination showed clumsiness of fine movements and a waddling gait. The patient was able to walk only 

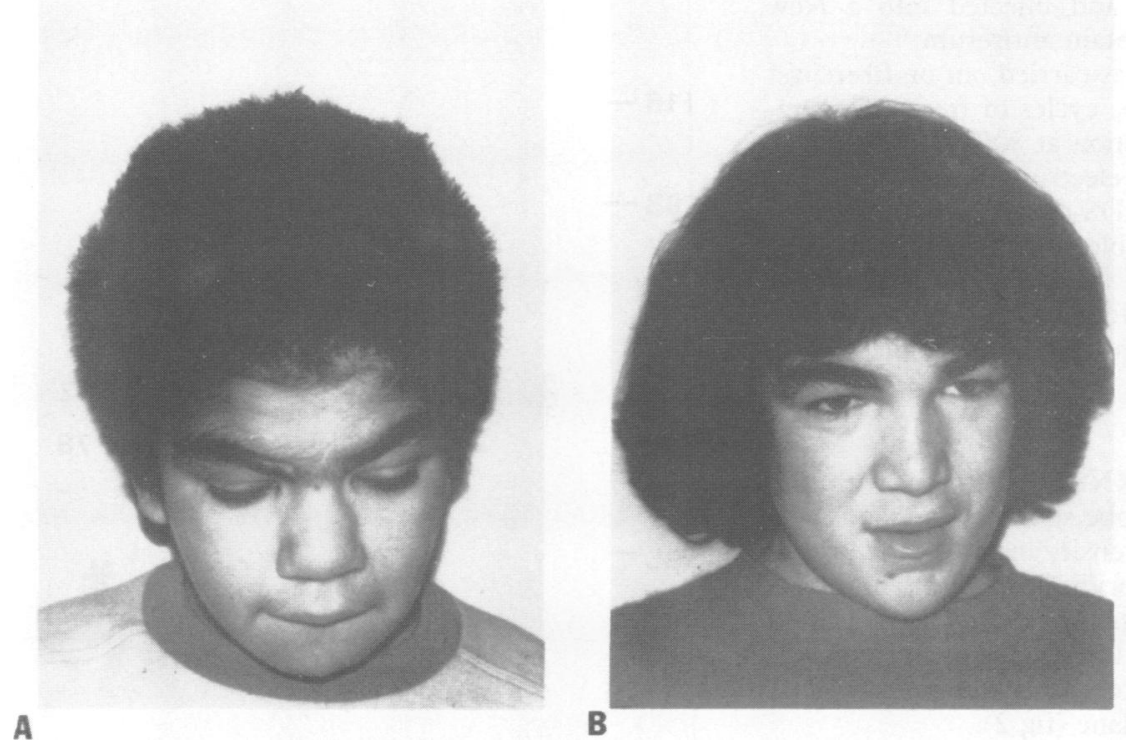

Figure 1 Patient 1 (A) at the age of 19 and patient $2(B)$ at the age of 14 .

if guided. Severe mental retardation was present with complete loss of speech. The ophthalmological examination showed retinal pigmentary degeneration. Radiological assessment displayed moderate kyphoscoliosis. Lumbar vertebral bodies had biconvex shape and irregular margins. Bilateral radial bowing with lateral convexity was present. Thin layer chromatography of the urine showed a spot typical of heparan sulphate. Lysosomal enzyme assays in skin fibroblasts indicated normal levels of 2-deoxyglucoside-2-sulphamate sulphatase, $\alpha$-N-acetylglucosaminidase, acetyl-CoA: $\alpha$-glucosaminide- $\mathrm{N}$-acetyltransferase, and arylsulphatase A and B. GlcNAc-6S sulphatase activity was not detectable (normal control $16 \mathrm{pmol} / \mathrm{min} / \mathrm{mg}$ cell protein), establishing the diagnosis of Sanfilippo syndrome type D.

\section{CASE 2}

Patient 2, a 14 year old girl, was born at term; birth weight was $3500 \mathrm{~g}$. According to the parents her psychomotor development was less delayed than that of her sister. She was able to walk at 12 months and began to speak at 18 months. However, her verbal communication was limited in articulation and content. She attended elementary school for five years with little advance. At the age of 11 years she began to show regression of her psychomotor achievements, the speech deteriorated, incoordination of fine motor activities developed, and leg stiffness and unsteady gait appeared. On clinical examination her height was $147 \mathrm{~cm}$ ( $3 \mathrm{rd}$ centile), weight $4500 \mathrm{~g}$ (10th centile), and head circumference $54 \mathrm{~cm}$ (50th centile). She had a coarse face and thick eyebrows. The nose had a wide base and the ears were small with large lobes. The hands were small and stubby. No hirsutism nor limitation of joint movements was present. The cardiac examination, including the EKG, was normal. The liver and spleen were not palpable. Neurological findings included clumsiness of fine movements, leg stiffness, and waddling gait. The patient showed severe mental retardation and her behaviour was characterised by episodes of restlessness and inappropriate interaction with her environment. Radiological examination showed biconvex lumbar vertebral bodies and bilateral radial bowing with lateral convexity. Thin layer chromatography of urine was positive for heparan sulphate. Fibroblasts showed complete absence of GlcNAc-6S sulphatase activity.

\section{Material and methods}

Northern blot analysis was carried out on mRNA isolated from fibroblasts of both patients and one normal control. ${ }^{8}$ Total RNA (20 $\mu \mathrm{g}$ ) was electrophoresed on $1 \%$ formaldehyde agarose gel and transferred onto nitrocellulose. Filter hybridisation was at $42^{\circ} \mathrm{C}$ for 16 hours in $50 \%$ formamide, $10 \%$ dextran sulphate, $1 \%$ SDS, $1 \mathrm{~mol} / \mathrm{l} \mathrm{NaCl}, 100 \mu \mathrm{g} / \mathrm{ml}$ denatured herring sperm DNA, and $10 \mathrm{ng} / \mathrm{ml}$ of ${ }^{32} \mathrm{P}$ 
labelled GlcNAc-6S sulphatase cDNA. $^{6}$ A $\beta$ hexosaminidase $\beta$ chain probe ${ }^{9}$ was used as a control. GlcNAc-6S sulphatase was purified from human liver as previously described ${ }^{5}$ and injected into a New Zealand white rabbit to obtain antiserum.

Western blot analysis was carried out on fibroblast lysates obtained after three cycles of freeze-thawing, sonication, and centrifugation at $8000 \mathrm{~g}$. The supernatant was subjected to electrophoresis on a $12 \%$ SDS-polyacrylamide gel (SDS-PAGE) and transferred to nitrocellulose by electroblotting. The nitrocellulose was immunostained with a 1:200 dilution of GlcNAc$6 \mathrm{~S}$ sulphatase antiserum followed by alkaline phosphatase conjugated goat anti-rabbit antibodies.

\section{Results}

Northern blotting of mRNA hybridised with the GlcNAc-6S sulphatase probe showed two bands at 5 $\mathrm{kb}$ and $4.2 \mathrm{~kb}$ of equal intensity in both patients and one normal control. Rehybridisation of the filter with a cDNA probe for $\beta$-hexosaminidase $\beta$ chain resulted in a positive signal at $2.2 \mathrm{~kb}$ of equivalent intensity, indicating that approximately equal amounts of RNA had been applied in each lane (fig 2).

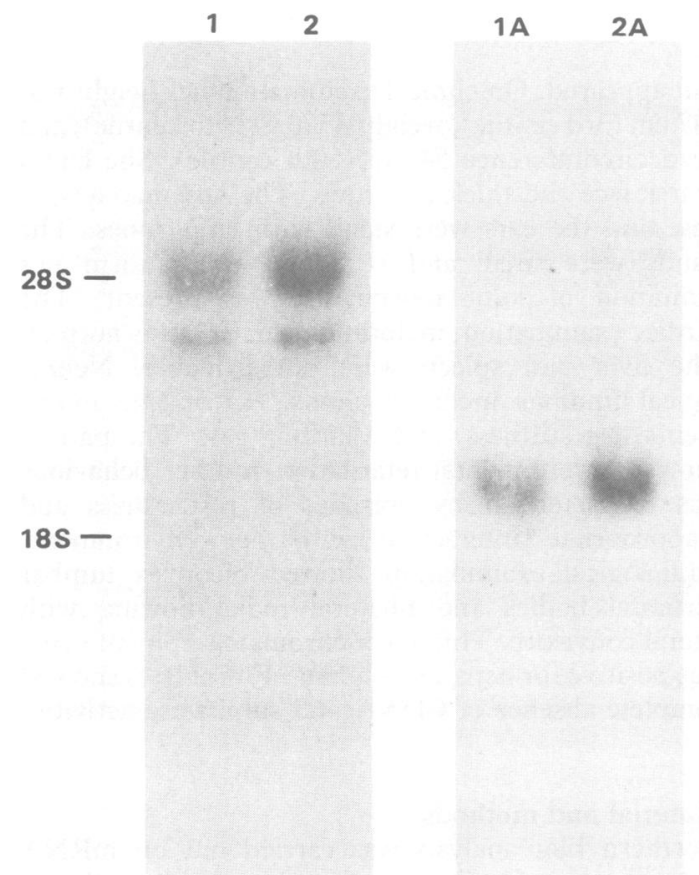

Figure 2 Analysis of GlcNAc-6S sulphatase by Northern blotting; 20 ug of RNA was electrophoresed in a formaldehydeagarose gel. The RNA was transferred onto nitrocellulose and probed with ${ }^{32} \mathrm{P}$ labelled cDNA encoding GlcNAc-6S

sulphatase. Lane 1 normal control, lane 2 patient 1 . Lanes $1 A$ and $2 A$ are the same lanes rehybridised with ${ }^{32} P$ labelled $c D N A$ encoding $\beta$-hexosaminidase $\beta$ chain.

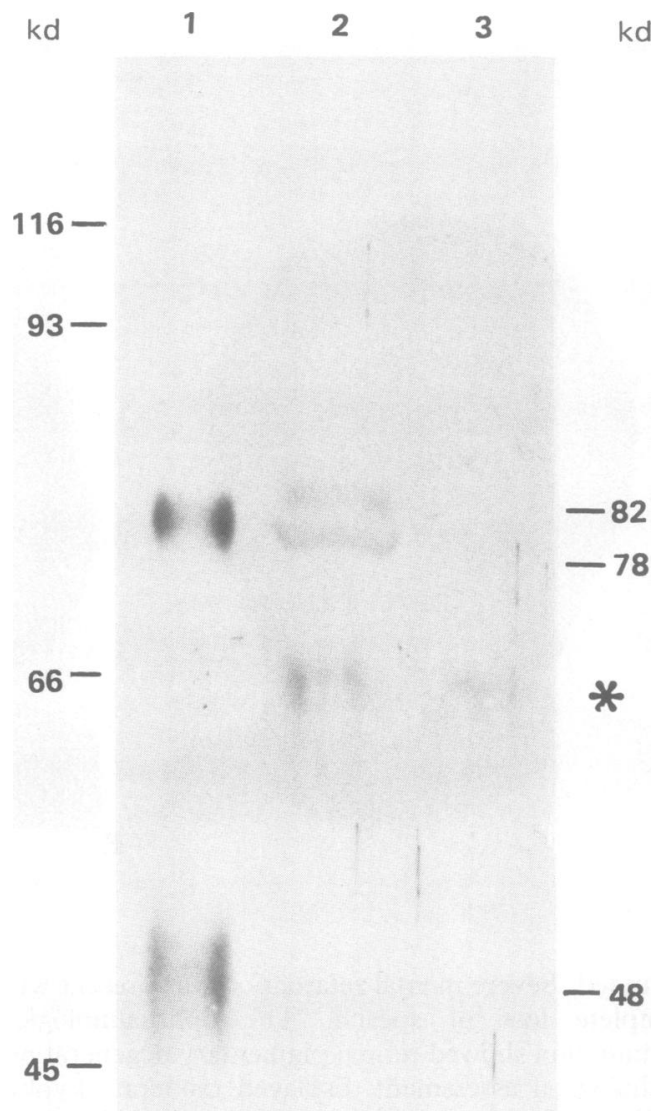

Figure 3 Western blot analysis of purified enzyme (lane 1) and of fibroblast lysates $(300 \mu \mathrm{g})$ from normal control (lane 2) and from patient I (lane 3) using antiserum for GlcNAc-6S sulphatase. *represents a non-specific contaminant inconsistently found in normal controls and Sanfilippo D patients.

SDS-PAGE and silver staining of the purified enzyme used to raise antibodies showed two major bands at molecular weight $78 \mathrm{kd}$ and $48 \mathrm{kd}$. Two similar bands of $78 \mathrm{kd}$ and $48 \mathrm{kd}$ were also detected by Western blotting of the purified enzyme immunostained with GlcNAc-6S sulphate antiserum. These bands correspond respectively to form $A$ and to the major peptide of form $B$ of the enzyme. ${ }^{5}$

Western blotting of fibroblast lysates from five normal controls showed two bands of $82 \mathrm{kd}$ and 78 $\mathrm{kd}$. In contrast, in our patients the $82 \mathrm{kd}$ band was absent and only a trace of the $78 \mathrm{kd}$ band was detectable (fig 3).

Endoglycosidase $\mathrm{H}$ treatment of fibroblast extracts followed by electrophoresis and immunoblotting resulted in a single band at $74 \mathrm{kd}$ (data not shown), indicating that the $82 \mathrm{kd}$ and $78 \mathrm{kd}$ forms derive from different carbohydrate processing of the same polypeptide. 
The $48 \mathrm{kd}$ band present in the preparation of purified enzyme from liver was never detectable in fibroblasts from patients and normal controls, suggesting that different forms of GlcNAc-6S sulphatase are present in different tissues.

\section{Discussion}

Sanfilippo syndrome is the most common of the mucopolysaccharidoses ${ }^{1}$ and is characterised by severe mental retardation and moderate somatic involvement. The first symptom is usually a mild delay of psychomotor development with onset between the ages of 2 to 6 years. Behavioural disturbances with irritability, aggressiveness, and progressive neurological deterioration follow, leading to dementia. Facial coarseness is less prominent than in other mucopolysaccharidoses. Growth retardation and corneal opacity are absent. Hepatosplenomegaly and bone dysplasia are mild. Sanfilippo syndrome type $A$ is slightly more severe than type $B$, with earlier clinical onset and earlier age at death. Type $C$ is considered intermediate in severity. ${ }^{9}$

So far, six cases of Sanfilippo syndrome type D have been described. The clinical symptoms follow the general pattern of Sanfilippo syndrome. Somatic signs are mild, always including coarse face, hirsutism, limitation of joint movements, and dysostosis multiplex. Mild to severe mental retardation has been reported in all patients.

Our patients exhibited the main clinical features described in the other cases of Sanfilippo syndrome type D, with the following differences. Both patients showed bilateral radial bowing, and no hirsutism or limitation of joint movements were present in patient 2. The course of the disease evolved rather differently in the two sisters. Psychomotor retardation in the infantile period was severe in patient 1 and only mild in patient 2. Neurological regression began at the age of 4 in patient 1 and at the age of 11 in her sister. In the previously reported cases of Sanfilippo syndrome type $D$, neurological regression occurred before the age of 4 in three cases, at the age of 8 in one, and was not evident in two patients (18 months old and 9 years old at the time of reporting). These findings may suggest the existence of two forms of Sanfilippo D syndrome according to the onset of mental and motor deterioration. Allelic mutations could be postulated for these clinical differences but, with respect to our patients, the occurrence of the two forms of the disease in the same sibship makes underlying genetic heterogeneity unlikely.

Our patients are the oldest reported with Sanfilippo syndrome type D. No increased susceptibility to infectious diseases or severe functional impairment of the viscera were noted. These observations suggest that the life expectancy of Sanfilippo syndrome type D is closer to type B (24 years) than to type A (14 years). ${ }^{10}$ However, the severe neurological deterioration observed in our patients implies a poor prognosis for quality of life even for those patients who may reach adult life.

By Northern blot hybridisation we showed that the patients' skin fibroblasts had normal size and quantity of mRNA encoding GlcNAc-6S sulphatase. This finding rules out the possibility that the DNA mutation in these cases results in abnormal transcription, yielding shortened or absent mRNA (for example, gene deletion or splice junction mutation), or in the formation of unstable RNA. Deficient GlcNAc-6S sulphatase cross reactive material was shown by Western blot analyses of fibroblast lysates from our patients. This suggests that a defective translation or a post-translational instability of the enzyme is the cause of Sanfilippo type D disease in these patients and is consistent with the nearly undetectable GlcNAc-6S sulphatase activity.

These studies, which further characterise Sanfilippo syndrome type $D$, may now form the basis for more extensive determination of the molecular defect in this disorder.

We are grateful to $\mathrm{Dr} \mathrm{H}$ Kresse for performing some enzyme assays. This work was supported in part by NIH grants HD24119 and HD04583 and the National Health and Medical Research Council of Australia.

1 Neufeld EF, Muenzer J. The mucopolysaccharidoses. In: Scriver CR, Beaudet AL, Sly WS, Valle D, eds. The metabolic basis of inherited diseases. New York: McGraw-Hill, 1989:1565-87.

2 Gatti R, Borrone C, Durand P, et al. Sanfilippo type D disease: clinical findings in two patients with a new variant of mucopolysaccharidosis III. Eur $\mathcal{f}$ Pediatr 1982;138:168-71.

3 Coppa GV, Giorgi PL, Felici L, et al. Clinical heterogeneity in Sanfilippo disease (mucopolysaccharidosis III) type D: presentation of two new cases. Eur $\mathcal{F}$ Pediatr 1983;140:130-3.

4 Kaplan P, Wolfe LS. Sanfilippo syndrome type D. J Pediatr 1987;110:267-71.

5 Freeman C, Clements PR, Hopwood JJ. Human liver N-acetylglucosamine-6-sulphate sulphatase. Biochem $\mathcal{f}$ 1987;246: $347-54$.

6 Robertson DA, Freeman C, Nelson PV, Morris CP, Hopwood JJ. Human glucosamine-6-sulfatase cDNA reveals homology with steroid sulfatase. Biochem Biophys Res Commun 1988;157: 218-24.

7 Freeman C, Hopwood JJ. Sanfilippo D syndrome: estimation of $\mathrm{N}$-acetylglucosamine-6-sulfatase activity with a radiolabelled monosulfated disaccharide substrate. Anal Biochem 1989;176: 244-8.

8 Chomczynski P, Sacchi N. Single-step method of RNA isolation by acid guanidinium thiocynate-phenol-chloroform extraction. Anal Biochem 1987;162:156-9.

9 O'Dowd BF, Quan F, Willard HF, et al. Isolation of cDNA clones coding for the beta-subunit of human beta-hexosaminidase. Proc Natl Acad Sci USA 1985;2:1184-8.

10 Van de Kamp JJP, Niermeijer MF, von Figura K, Giesberts NAH. Genetic heterogeneity and clinical variability in the Sanfilippo syndrome (type A, B and C). Clin Genet 1981;20: $152-60$. 